\title{
Changes in colonic motility induced by sennosides in dogs: evidence of a prostaglandin mediation
}

\author{
G STAUMONT, J FIORAMONTI, J FREXINOS, AND L BUENO
}

From the Department of Pharmacology INRA and the Department of Gastroenterology, Rangueil Hospital, Toulouse, France

SUMmaRy The effects of sennosides on colonic motility were investigated in eight conscious dogs chronically fitted with two strain gauge transducers in the proximal colon, an intracolonic silicone catheter and a polyethylene catheter implanted in a branch of the right colonic artery. Oral sennosides $(30 \mathrm{mg} / \mathrm{kg}$ ) inhibited colonic motility for 12 to $18 \mathrm{~h}$ after a three to six hours delay, and associated with giant contractions and diarrhoea. The minimal oral dose of sennosides to produce such changes varied from 5 to $15 \mathrm{mg} / \mathrm{kg}$. Intracolonic sennosides at the minimal effective dose and at $30 \mathrm{mg} / \mathrm{kg}$ reproduced the effects of oral sennosides, but with a shorter latency $(0 \cdot 5-1 \cdot 5 \mathrm{~h})$. Intracolonic PGE $(100 \mu \mathrm{g} / \mathrm{kg})$ in viscous gel medium or intra-arterial PGE $(10 \mu \mathrm{g} / \mathrm{h})$ inhibited colonic motility and induced giant contractions often associated with defecation. The colonic motor changes induced by intracolonic sennosides at the minimal effective dose, but not those induced by intracolonic PGE 2 , were blocked by intra-arterial indomethacin $(10 \mu \mathrm{g} / \mathrm{h})$ or piroxicam $(5 \mu \mathrm{g} / \mathrm{h})$. These results suggest that colonic motor actions of sennosides are mediated through a local prostaglandins synthesis, as they were blocked by cyclooxygenase inhibitor and reproduced by $\mathrm{PGE}_{2}$.

Sennosides, the main laxative components of senna extracts, which chemically belong to the anthraquinones, are known to induce fluid secretion in the colon $^{12}$ and to modify colonic motility. ${ }^{3-5}$ Because of their dianthrone- $\beta$-glycoside structure a bacterial degradation of sennosides is necessary to obtain active laxative metabolites. ${ }^{6}$ For this reason sennosides are pharmacologically inert in the upper gastrointestinal tract and have an action localised at the colonic level.

The effects of sennosides on colonic motility remain controversial: a stimulation of peristaltic pressure waves has been reported in human after intraluminal administration through a colostomy ${ }^{3}$ whereas a reduction of the intracolonic pressure ${ }^{5}$ and a long lasting inhibition of the colonic myoelectrical activity ${ }^{4}$ have been described after oral administration in man and dogs respectively. These discrepan-

Address for correspondence: Dr J Fioramonti, Station de Pharmacologie, INRA, 180 chemin de Tournefeuille, 31300 Toulouse, France.

Received for publication 11 March 1988. cies may be attributed to differences in methodology, the intraluminal application not being a classical route and the electromyography technique not taking into account the amplitude of contractions. The first aim of this study was, to describe the changes in colonic motility induced by oral administration of pure sennosides in the dog, a species characterised by a well defined colonic motor profile.

The secretory effects of sennosides have been shown to be mediated through a prostaglandin synthesis as they are blocked by indomethacin. ${ }^{28}$ Prostaglandins are also known to modify colonic motility. Prostaglandin E has been found to induce a persistaltic activity in isolated longitudinal strips of colon associated with a relaxation of circular muscles, ${ }^{9}$ to decrease sigmoid intraluminal pressure ${ }^{10}$ and to accelerate small intestine and colonic transit time. ${ }^{11}$ Moreover a recent study suggests that the colonic transit accleration was a primary mechanism in $\mathrm{PGE}_{2}$-induced diarrhoea. ${ }^{12}$ The second goal of this study was to determine whether the motor effects of sennosides were mediated through a prostaglandin 
synthesis. Consequently attempts to block the effects of sennosides by indomethacin and to reproduce them by $\mathrm{PGE}_{2}$ administrations were done. Because of the strong ulcerogenic action of indomethacin in $\operatorname{dogs}^{13}$ and the complete inactivation of prostaglandins by lungs, ${ }^{1+}$ indomethacin and $\mathrm{PGE}_{2}$ were locally infused through a catheter chronically inserted in a colonic artery.

\section{Methods}

\section{ANIMÁLS}

Eight mongrel dogs, $20-25 \mathrm{~kg}$ in weight, were used in these experiments. Under halothane anaesthesia, a small polyethylene catheter (Biotrol Pharma, Paris, id $0.30 \mathrm{~mm}$, od $0.70 \mathrm{~mm}$ ) was inserted into a ramification of the right colonic artery in the opposite direction of the bloodstream according to a technqiue previously described for a jejunal artery. ${ }^{15}$ The catheter was pushed into the artery over a distance of about $2 \mathrm{~cm}$ in such a way that the tip was located just at the site of bifurcation of the artery. It was fixed to the artery and the mesentery with 2:0 polyester sutures (Fig. 1). The location and the size of the perfused segment was visualised by injecting metylene blue into the catheter. The location was $6-8 \mathrm{~cm}$ from the ileocolonic junction and the size was $3-5 \mathrm{~cm}$.

Two strain gauge transducers constructed in our

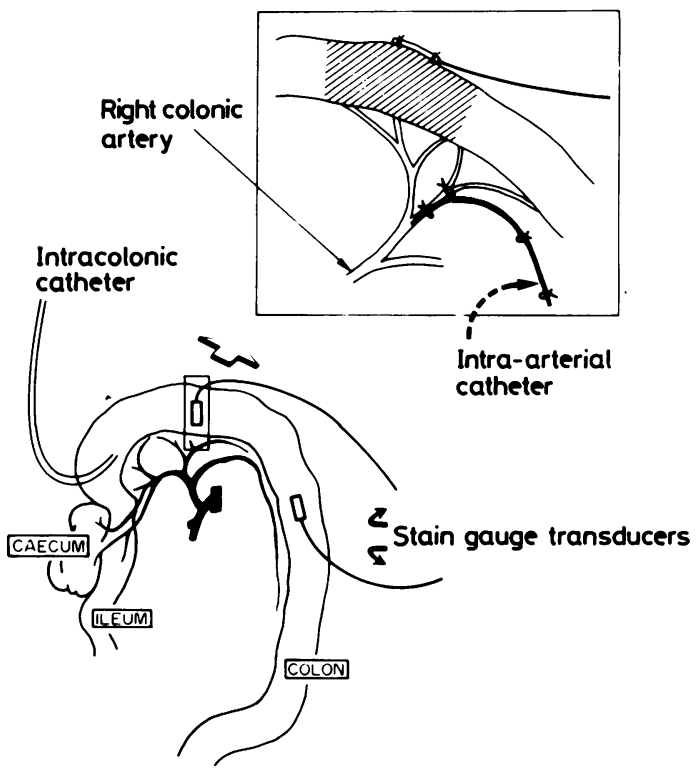

Fig. 1 Representation of selective intra-arterial infusion technique on canine colon. The catheter was introduced upstream into an arterial ramification until the vessel bifurcation. laboratory were sutured to the serosa of the colon, one on the perfused segment and one $10 \mathrm{~cm}$ aborally. Each transducer had its recording axis parallel to the transverse axis of the colon in order to measure the contractile force of the circular muscle layer.

A silicone catheter (Versilic ND, Verneret, Paris, id $1 \mathrm{~mm}$, od $3 \mathrm{~mm}$ ) was inserted into the colonic lumen at $3 \mathrm{~cm}$ from the ileocolonic junction. The free ends of the strain gauge wires, the intra-arterial and intracolonic catheters were directed subcutaneously along the flank to emerge dorsally between the scapulas. Both catheters remained permeable for two to four months.

\section{RECORDINGS}

Calibration of each strain gauge was carried out before implantation. The colonic mechanical activity detected by the two transducers was recorded by connecting the strain gauges to a Wheatstone bridge amplifier (VT 2100, Vishay, France) connected to a potentiometric recorder (RK4 Rikadenki, Toshin, Japan) with a paper speed of $1 \mathrm{~mm} / \mathrm{min}$. The motility index at each of the two colonic sites was determined by means of a quantitative computerised analysis using a microcomputer data processor (Epson HX 20 ) according to the technique of Hachet et al. ${ }^{16}$ The motility index calculated by the processing system, which reported values at 60 min intervals, corresponded to the measurement of the area between the baseline and the contractile curve.

\section{EXPERIMENTAL PROCEDURE}

The dogs were maintained in cages for recordings over 22 consecutive hours (from 830 to $630 \mathrm{am}$ ). Immediately after surgery the arterial catheter was continuously $(22 / 24 \mathrm{~h})$ perfused with a diluted heparin solution $(1000 \mathrm{UI} / \mathrm{ml}, 2 \mathrm{ml} / 24 \mathrm{~h})$ by means of an insulin infusion pump (Syringe driver, Type MS16, Pye Dynamics, Bushey, UK). Dogs were fed once a day at $900 \mathrm{am}$ with a mixture of $250 \mathrm{~g}$ canned (Fido) and $250 \mathrm{~g}$ dry (Royal Canine) food for dogs.

The sennosides used in these experiments (a gift from Madaus \& Co, Koln, W Germany) consisted of dried purified senna containing $92 \%$ of sennosides A and $B, 5 \%$ of sennosides $A_{1}, C$ and $D, 3 \%$ of water. Sennosides were given at a standard dose of $30 \mathrm{mg} / \mathrm{kg}$ orally or by intracolonic route. The minimal effective dose of sennosides was determined by $5 \mathrm{mg} / \mathrm{kg}$ successive increases from an initial dose of $5 \mathrm{mg} / \mathrm{kg}$ until an effect on colonic motility appeared. Sennoside administrations were done three hours after the daily meal.

$\mathrm{PGE}_{2}$ was injected intracolonically at a dose of $100 \mu \mathrm{g} / \mathrm{kg}$ using a gel preparation (Dinoprostone gel, Upjohn, Crawley, UK) or infused intra-arterially at a rate of $10 \mu \mathrm{g} / \mathrm{h}\left(\mathrm{PGE}_{2}\right.$ purchased from Sigma, St 
Louis, MO). Intracolonic administrations of $\mathrm{PGE}_{2}$ were given three hours after the meal and the intraarterial infusion began three hours after the meal and lasted three hours.

Attempts to block the motor effects of intracolonic administration of sennosides at the minimal effective dose or of $\mathrm{PGE}_{2}(100 \mu \mathrm{g} / \mathrm{kg})$ were carried out by intra-arterial infusion of indomethacin (Sigma, St Louis, MO) at a rate of $10 \mu \mathrm{g} / \mathrm{h}$, piroxicam (a gift from Pfizer, Orsay, France) at a rate of $5 \mu \mathrm{g} / \mathrm{h}$. The infusions started two hours before intracolonic administrations of sennosides or $\mathrm{PGE}_{2}$ and lasted seven hours. Indomethacin and piroxicam were also intra-arterially infused alone at the same rate and during the same postprandial period in each dog.

Sennosides and piroxicam were dissolved in saline, indomethacin in a $5 \%$ solution of $\mathrm{NaHCO}_{3} . \mathrm{PGE}_{2}$ was dissolved in absolute ethanol $(10 \mathrm{mg} / \mathrm{ml})$ and stored at $-20^{\circ} \mathrm{C}$; further dilutions were made weekly and stored at $4^{\circ} \mathrm{C}$. The intra-arterial infusion rate of drugs was $0.2 \mathrm{ml} / \mathrm{h}$ and controls were performed with infusions of vehicle at the same rate. The controls for the effects of intracolonic administrations of sennosides or $\mathrm{PGE}_{2}$ were intracolonic injection of saline $(5 \mathrm{ml})$ or excipient of $\mathrm{PGE}_{2}$ gel $(5 \mathrm{ml})$ respectively. Each experiment was done once in each dog with a minimal interval of 48 hours. The location and the permeability of the arterial catheter was checked daily by a rapid arterial blood inflow in the tube when it was disconnected from the pump.

STATISTICAL ANALYSIS

The motility indexes reported each hour after sennoside or $\mathrm{PGE}_{2}$ administration (expressed in $\mathrm{g} \mathrm{min} / \mathrm{h}$ and given as mean (SD)) were compared with those observed during the same period in control studies with administration of the respective vehicle in the same animals. Because of variable delay for the inhibitory action of sennosides after oral administration a period of colonic motor inhibition was defined as the time including consecutive hourly motility indexes with values lower than $30 \%$ of mean motility index determined over 10 hours after vehicle administration. The changes in colonic motility index during this period of inhibition were expressed as percentage of control values reported at the same time after vehicle administration. In attempts to block the action of sennosides or $\mathrm{PGE}_{2}$ intracolonically administered by intra-arterial infusions of indomethacin or piroxicam, motility indexes were compared during a period comprised between three and five hours after the beginning of the intra-arterial infusion - that is, between one and three hours after intracolonic administration of sennosides or $\mathrm{PGE}_{2}$.

The number of peculiar colonic contractions sometimes associated with defecation, previously described as giant contractions ${ }^{17}$ was measured by visual inspection of the records and expressed as mean (SD). A contraction was considered as giant when its amplitude was at least two times higher of the mean amplitude of contractions during the same hourly period in control experiments. Comparisons were performed using a T Wilcoxon's test for paired values.

\section{Results}

\section{CONTROL}

In absence of any treatment, each dog exhibited the typical pattern of colonic motility already described. ${ }^{7}$ During a period comprised between three and 13 hours after meal, it consisted of contractions grouped in phases lasting $8.9(2.8) \mathrm{min}$, occurring at intervals of $18.4(5.1)$ min (mean (SD) for eight animals) and corresponding to a mean motility index of $9 \cdot 3(2 \cdot 7) \mathrm{g}$ $\mathrm{min} / \mathrm{h}$. Administrations of vehicle of each drug used in this study did not significantly $(p<0.05)$ modify the motility index.

EFFECTS OF SENNOSIDE ADMINISTRATIONS Oral administration of sennosides at a dose of $30 \mathrm{mg} /$ $\mathrm{kg}$ induced an inhibition of colonic motility lasting 12 to 18 hours and appearing after a delay varying from three to six hours (Fig. 2, Table 1). Abundant

Table 1 Changes in motility index and number of giant contractions induced by administration of oral and intracolonic sennosides and intracolonic (IC) and intra-arterial (IA) $P G E_{2}$.

\begin{tabular}{|c|c|c|c|c|c|c|c|}
\hline & \multirow[b]{2}{*}{ Control } & \multicolumn{2}{|c|}{ Sennosides per OS } & \multicolumn{2}{|c|}{ Intracolonic sennosides } & \multirow[b]{2}{*}{$\begin{array}{l}P G E_{2} I C \\
100 \mu \mathrm{g} / \mathrm{kg}\end{array}$} & \multirow[b]{2}{*}{$\begin{array}{l}P G E_{2} I A \\
10 \mu g / h\end{array}$} \\
\hline & & $30 \mathrm{mg} / \mathrm{kg}$ & $\begin{array}{l}\text { Minimal } \\
\text { effective dose }\end{array}$ & $30 \mathrm{mg} / \mathrm{kg}$ & $\begin{array}{l}\text { Minimal } \\
\text { effective dose }\end{array}$ & & \\
\hline $\begin{array}{r}\text { Motility index } \\
(\% \text { control })\end{array}$ & 100 & $15(4 \cdot 7)$ & $22(7 \cdot 3)$ & $10 \cdot 3(5 \cdot 9)$ & $17(7)$ & $13(5 \cdot 2)$ & $20(8 \cdot 5)$ \\
\hline Giant contractions $(n)$ & 0 & $10 \cdot 6(4 \cdot 4)$ & $6 \cdot 8(3 \cdot 8)$ & $11 \cdot 5(3 \cdot 9)$ & $5 \cdot 9(2 \cdot 7)$ & $3 \cdot 3(1 \cdot 8)$ & $1.9(0.9)$ \\
\hline
\end{tabular}

Values are mean (SD) from eight dogs. Changes in motility index were expressed as the percentage of control motility index during the same period after drug or vehicle administration. 
Control
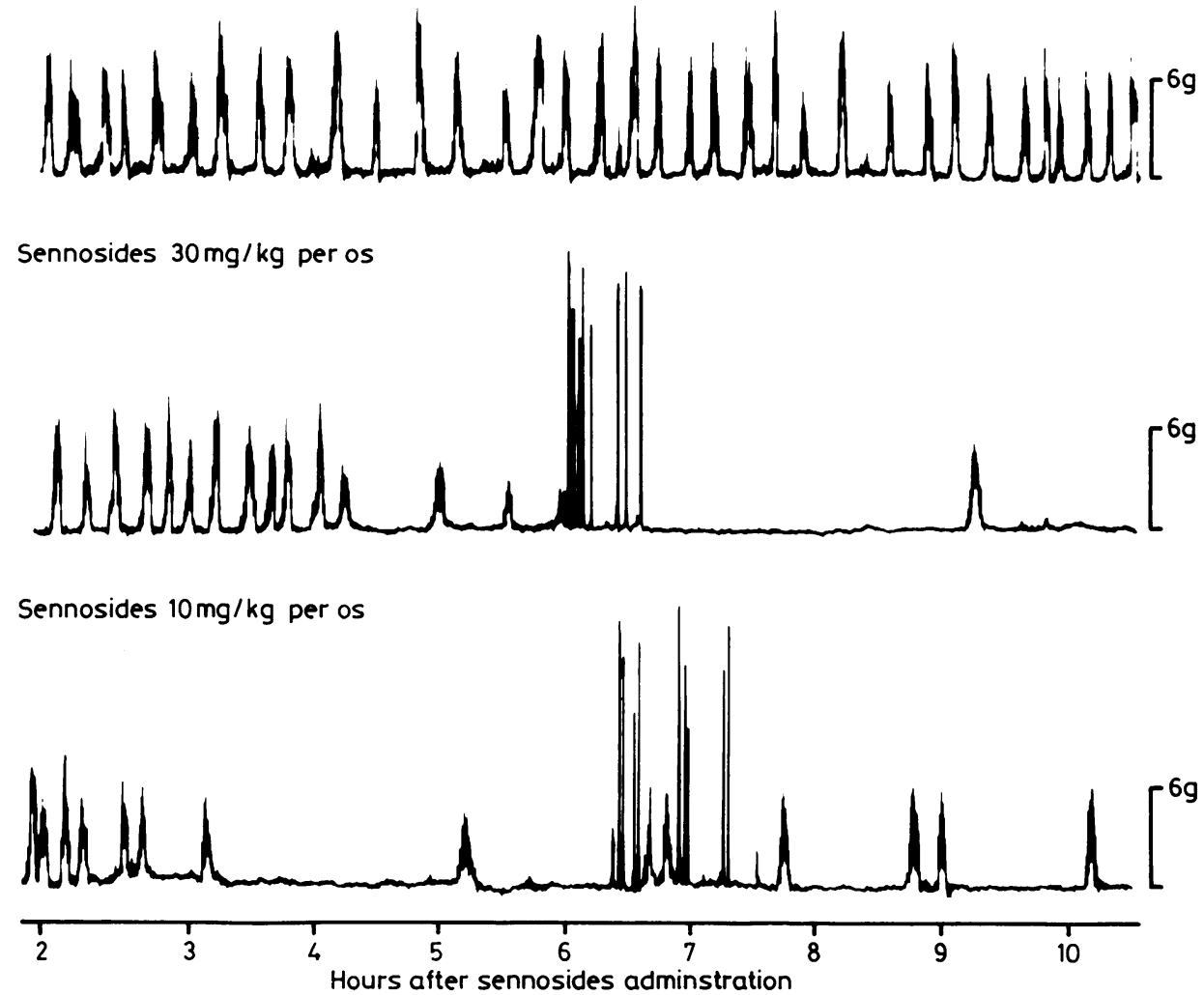

Fig. 2 Changes in mechanical activity of the proximal colon observed in the same dog after oral administration of sennosides at $30 \mathrm{mg} / \mathrm{kg}$ and at 'the minimal effective dose' (10 $\mathrm{mg} / \mathrm{kg}$ for this dog). They consisted of a motor inhibition associated with 'giant migrating contractions' and defecation.

diarrhoea always occurred four to 10 hours after sennoside administration. Giant contractions, lasting about one minute and with an amplitude two to three times higher than that of other contractions appeared during this period of inhibition and were often associated with defecation. Each diarrhoeic defecation corresponded to a giant contraction but each giant contraction was not associated with defecation. The minimal effective dose required to induce these disturbances of colonic motility and diarrhoea varied between 5 to $15 \mathrm{mg} / \mathrm{kg}$. The duration of the colonic inhibition after the minimal effective dose was shorter than that induced by the dose of $30 \mathrm{mg} / \mathrm{kg}$ and similarly the number of giant contractions was lower (Table 1). The reduction of the motility index observed after the minimal dose did not significantly differ however $(p>0.05)$ from that induced by the $30 \mathrm{mg} / \mathrm{kg}$ dose (Table 1 ).

Intracolonic injection of sennosides induced diarrhoea, giant contractions and an inhibition of the basal colonic motility similar in duration and ampli- tude to that observed after oral administration at the same dosage. For each dog the minimal effective dose of sennosides intracolonically administered was identical to that determined after oral administration. The only difference observed between the two routes of administration was a shorter delay $(0.5$ to $1.5 \mathrm{~h}$ ) in the appearance of the colonic inhibition after intracolonic administration.

\section{EFFECTS OF PGE 2 ADMINISTRATION}

Intracolonic administration of $\mathrm{PGE}_{2}$ (Dinoprostone gel TM) at a dose of $100 \mu \mathrm{g} / \mathrm{kg}$ induced changes in colonic motility roughly similar to that observed after intracolonic administration of sennosides (Fig. 3). A significant $(p>0.01)$ decrease in colonic motility index (Table 1) occurred after less than one hour and lasted two to four hours. Giant contractions appeared in six of the eight dogs used, usually with diarrhoeic defecation (five of eight dogs).

Infusion of $\mathrm{PGE}_{2}$ into a colonic artery at a dose of $10 \mu \mathrm{g} / \mathrm{h}$ for three hours reproduced the effects of 

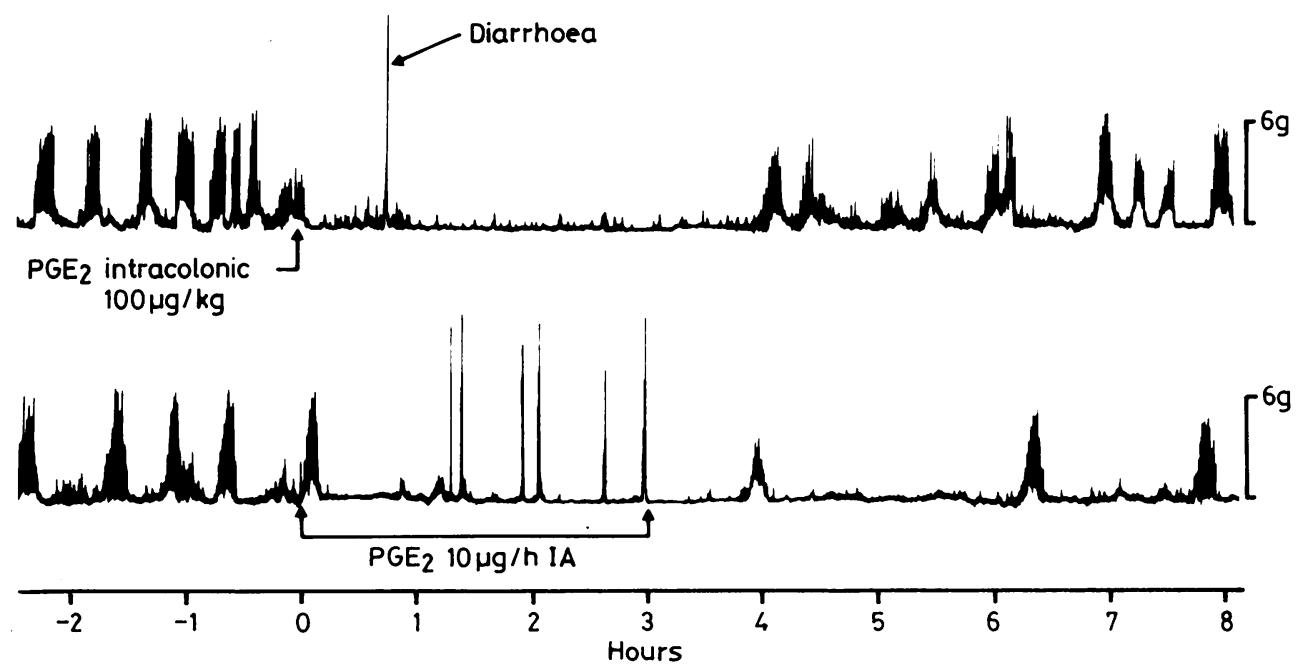

Fig. 3 Effects of $P G E_{2}$ on mechanical activity of the proximal colon using intracolonic administration and intra-arterial (IA) infusion in the same dog. A motor inhibition appeared associated to 'giant migrating contractions' and sometimes defecation.

their intracolonic administration. An inhibition of similar amplitude appeared within 30 minutes after the beginning of the infusion and lasted for one to three hours after the end of the infusion (Table 1). Giant contractions and diarrhoea were observed in six of the eight dogs.

\section{ANTAGONISM OF COLONIC MOTOR EFFECTS OF SENNOSIDES}

The inhibitory effect of sennosides on colonic motility was suppressed (Figs. 4,5 ), when they were introduced into the colon at the minimal effective dose during an intra-arterial infusion of indomethacin $(10 \mu \mathrm{g} / \mathrm{h})$. The number of giant contractions was significantly $(p<0.05)$ reduced (Table 2$)$ and diarrhoeic defecation occurred in only one dog. Similarly piroxicam intra-arterially infused $(5 \mu \mathrm{g} / \mathrm{h})$ abolished the inhibitory action of intracolonic sennosides and significantly $(\mathrm{p}<0.05)$ reduced the number of giant contractions (Fig. 5, Table 2). The motor colonic effects of intracolonic administration of
$\mathrm{PGE}_{2}(100 \mu \mathrm{g} / \mathrm{kg})$ were not modified by the intraarterial infusion of indomethacin or piroxicam (Fig. 5 , Table 2).

An intra-arterial infusion of indomethacin $(10 \mu \mathrm{g} / \mathrm{h})$ or piroxicam $(5 \mu \mathrm{g} / \mathrm{h})$ alone did not produce any change of colonic motility (Fig. 5, Table 2).

\section{Discussion}

Our results indicate that sennosides inhibit colonic motility in dogs and induce high amplitude contractions associated with diarrhoeic defecations. They suggest that these motor effects are mediated through a prostaglandin synthesis as they are in part suppressed by indomethacin or piroxicam and are reproduced by intracolonic and intra-arterial $\mathrm{PGE}_{2}$.

Interpretation of the effects of intravenous administration of drugs is limited by the interaction of several systems affecting the drug and by unknown pharmacokinetic data of the drug at the level of

Table 2 Number of giant contractions induced by intracolonic sennosides and $P G E_{2}$ during arterial infusion of indomethacin or piroxicam or of their respective vehicle.

\begin{tabular}{lllll}
\hline & \multicolumn{2}{l}{ Intra-arterial infusion $(0 \cdot 2 \mathrm{ml} / \mathrm{min})$} & \\
\cline { 2 - 5 } Intracolonic administration & $\begin{array}{l}\text { Vehicle of } \\
\text { indomethacin }\end{array}$ & $\begin{array}{l}\text { Indomethacin } \\
(10 \mu \mathrm{g} / \mathrm{h})\end{array}$ & $\begin{array}{l}\text { Vehicle of } \\
\text { piroxicam }\end{array}$ & $\begin{array}{l}\text { Piroxicam } \\
(5 \mu \mathrm{m} / \mathrm{h})\end{array}$ \\
\hline Sennosides $($ minimal effective dose) & $5 \cdot 3(1 \cdot 8)$ & $3 \cdot 4(2 \cdot 4)^{*}$ & $4.9(0 \cdot 8)$ & $2.9(2 \cdot 3)^{*}$ \\
PGE $_{2}(100 \mu \mathrm{g} / \mathrm{kg})$ & $2 \cdot 0(0 \cdot 8)$ & $2 \cdot 2(1 \cdot 1)$ & $1 \cdot 6(0 \cdot 7)$ & $2 \cdot 3(1 \cdot 4)$ \\
\hline
\end{tabular}

Values are mean (SD) from eight dogs. Giant contractions were counted for 15 hours after the beginning of the intra-arterial infusion.

*Significantly different $(p<0.05)$ from values obtained with using arterial infusion of vehicle. 

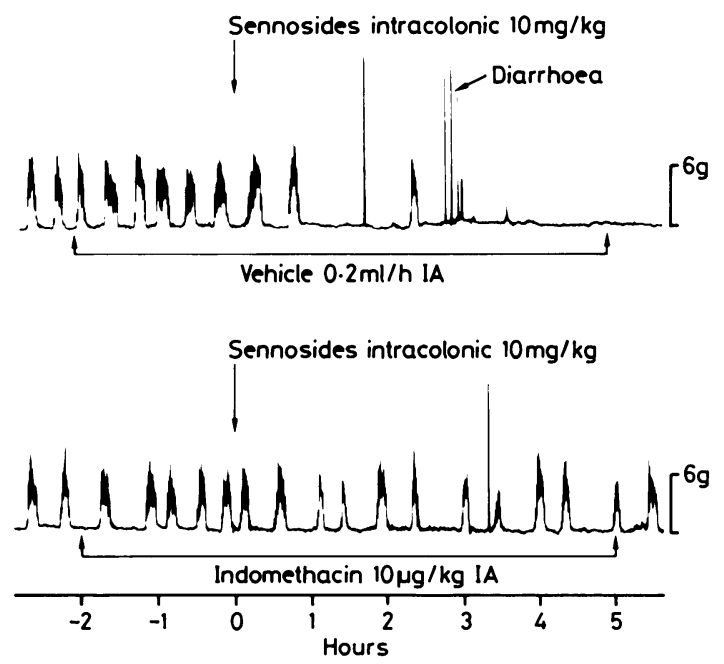

Fig. 4 Effects of an intra-arterial (IA) indomethacin infusion on the colonic motor pattern induced by intracolonic sennosides at the 'minimal effective dose' $(M E D)$ in the same dog. The motor inhibition and diarrhoeic defecation were suppressed and the number of the 'giant migrating contractions' was reduced during indomethacin infusion.

the target organ. The interpretation of our results obtained with prostaglandins is more accurate using an intra-arterial infusion than an intravenous administration as prostaglandins are widely distributed in the organism, have a very short half life and no storage, and are rapidly inactivated during a single passage through the pulmonary circulation..$^{14}$ Moreover indomethacin is known to be highly ulcerogenic in dogs by comparison with other animal species. ${ }^{13}$ Intra-arterial infusion of indomethacin at a low dosage avoided gastric ulcer formation.

The changes in colonic motility induced by oral administration of sennosides are partially in agreement with a previous study carried out in dogs ${ }^{4}$ showing an inhibition of colonic motility. This study ${ }^{4}$ did not describe the giant contractions seen in our experiments, however probably because of the use of an electromyographic method instead of the measurement of the contractile force. The giant contractions have been always described using strain gauge transducers ${ }^{1718}$ and taking into account their short duration, their detection on a colonic electromyogram is probably not easy. Inhibition of colonic motility and presence of giant contractions associated with defecation seem to be common features of laxative induced changes in colonic motility as they were previously observed with castor oil and magnesium citrate. ${ }^{18}$

The latency of three to six hours between the oral administration of sennosides and the appearance of

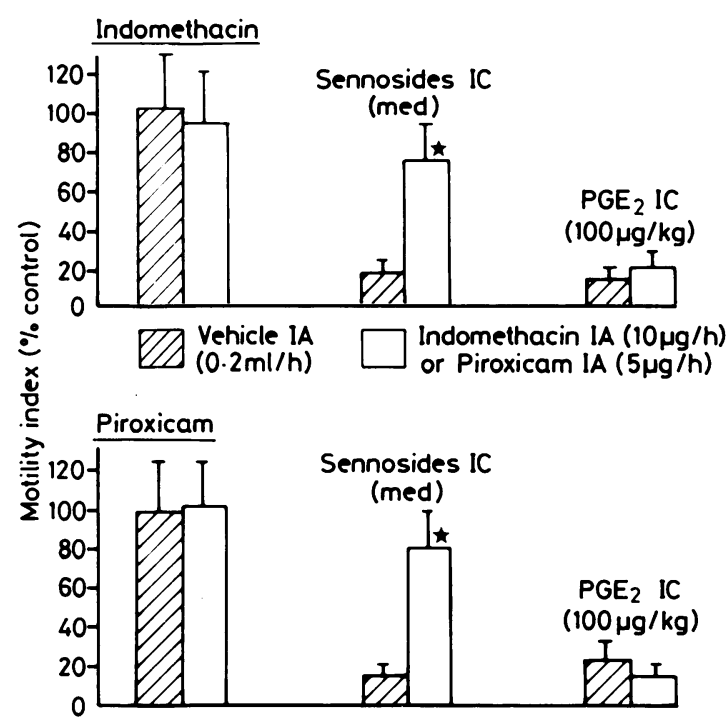

Fig. 5 Comparative antagonism of intra-arterial (IA) indomethacin and piroxicam on changes in colonic motility index induced by intracolonic (IC) sennosides given at the minimal effective dose (MED) or PGE $(100 \mu \mathrm{g} / \mathrm{kg})$. Values were determined from one to three hours after intracolonic administration of sennosides or $P G E_{2}$ and are mean $\pm S D$ from eight dogs. *Significantly different $(p<0.01)$ from values obtained with vehicle intra-arterial infusion of vehicle. Control $(100 \%)$ corresponded to the motility index without any administration.

the colonic motor disturbances probably corresponds to the orocolonic transit and was similar to that observed with other laxatives. ${ }^{18}$ Sennosides are inert in the upper gastrointestinal tract ${ }^{6}$ however, while other laxative compounds such as castor oil have been found to modify small intestinal contractile activity. ${ }^{19}$ Moreover the sennoside induced changes in colonic motility observed in dogs present some similarities with the decrease in sigmoid intraluminal pressure $^{5}$ and the large amplitude contractions ${ }^{3}$ appearing after intraluminal application in man.

Several laxatives ${ }^{20}$ and particularly sennosides, ${ }^{2}$ are known to alter epithelial fluid transport resulting in net fluid accumulation. The question arises whether the disturbances of colonic motility are caused by a direct action of sennosides or are a consequence of fluid secretion. In dogs it has been shown that infusion of large amounts of a hypertonic solution of mannitol did not reproduce the colonic inhibition induced by sennosides or other laxatives but on the contrary, stimulated the basal colonic motility. ${ }^{21} \mathrm{On}$ the other hand, after oral administration of sennosides in rats, the acceleration of the colonic transit preceded the net fluid secretion. ${ }^{22}$ These two data indirectly favour direct action of sennosides on 
colonic motility and not a consequence of fluid secretion.

Senna extracts have been found to increase prostaglandin formation in the rat colon. ${ }^{28}$ On the other hand inhibition of prostaglandin synthesis by indomethacin has been found to antagonise the secretory action of sennosides in the rat colon. ${ }^{28}$ Our data indicate that the colonic motor effects of sennosides are also mediated through a local prostaglandin synthesis.

Indomethacin inhibits fatty acid cyclo-oxygenase but also inhibits calcium accumulation by mitochondria and microsome. ${ }^{23} \mathrm{~A}$ blockade of the effects of sennosides by indomethacin may be attributed to an inhibition of prostaglandin synthesis but also to an action on intracellular calcium movements and it has been shown that the action of sennosides on intestinal electrolyte transport was calcium dependent. ${ }^{1}$ The blockade of the colonic motor effects by piroxicam which is a cyclo-oxygenase inhibitor without action on calcium uptake, ${ }^{23}$ indicates that the sennoside induced motor effects depend upon prostaglandin synthesis. Moreover these motor effects are reproduced by intra-arterial or intraluminal administration of $\mathrm{PGE}_{2}$. These results are not in complete agreement with recent data showing that intracolonic administration of $\mathrm{PGE}_{2}$ did not modify colonic transit time and did not induce diarrhoea in rats. ${ }^{2+}$ Such discrepancy may be attributed to differences in the solvant use. In the first study ${ }^{2+} \mathrm{PGE}_{2}$ were dissolved in saline whereas in our study $\mathrm{PGE}_{2}$ were in a viscous gel medium, used for endocervical application ${ }^{25}$ which probably permitted a slow release of the compound in the colonic lumen. The $\mathrm{PGE}_{2}$-induced inhibition of colonic motility described herein, however may be related to the relaxation of colonic circular muscle reported using in vitro preparations ${ }^{9}$ and confirmed by the decrease in sigmoid intraluminal pressure observed after intravenous administration of $\mathrm{PGE}_{2}$ in man. ${ }^{10}$ Moreover, an analogy could be pointed out between the giant contractions and the $\mathrm{PGE}_{2}$-induced stimulation of peristaltic activity of isolated longitudinal strips of colon. ${ }^{9}$ Furthermore, the inhibition of basal cyclic contractions and giant contractions seem to be a common feature of laxatives involving prostaglandins as it also appeared after castor oil administration ${ }^{18}$ which increased colonic prostaglandin production ${ }^{2627}$ but not after hypertonic mannitol infusion ${ }^{21}$ which did not modify the prostaglandin formation. ${ }^{26} 27$

Finally, our results indicate that sennosides induced a colonic motor pattern which may play a role in prostaglandin mediated diarrhoea.

The authors thank C Betoulieres, G Bories, M Caussette, and C Santamaria for their assistance.

\section{References}

1 Donowitz M, Wicks J, Battisti L, Pike G, De Lellis R. Effect of Senokot on rat intestinal electrolyte transport. Evidence of $\mathrm{Ca}^{++}$dependence. Gastroenterology 1984; 87: 503-12.

2 Beubler E, Kollar G. Stimulation of $\mathrm{PGE}_{2}$ synthesis and water and electrolyte secretion by senna anthraquinones is inhibited by indomethacin. J Pharm Pharmacol 1985; 37: 248-51.

3 Hardcastle JD, Wilkins JL. The action of sennosides and related compounds on human colon and rectum. Gut 1970; 11: 1038-42.

4 Garcia-Villar R, Leng-Peschlow E, Ruckebusch Y. Effect of antraquinone derivatives on canine and rat intestinal motility. J Pharm Pharmacol 1980; 32: 323-9.

5 Waller SL. Comparative effect of codeine and senna on motor activity of the left colon. Gut 1975; 16: 407-8.

6 Lemli J, Lemmens L. Metabolism of sennosides and rhein in the rat. Pharmacology 1980; 20(suppl 1): 50-7.

7 Fioramonti J, Bueno L. Diurnal changes in colonic motor profile in conscious dogs. Dig Dis Sci 1983; 28: 257-64.

8 Capasso F, Mascolo N, Autore G, Duraccio MR. Effect of indomethacin on aloin and 1.8 dioxianthraquinoneinduced production of prostaglandins in rat isolated colon. Prostaglandins 1983; 26: 557-62.

9 Bennett A, Fleshler B. Prostaglandins and the gastrointestinal tract. Gastroenterology 1970; 59: 790-800.

10 Hunt RH, Dilawari GB, Misiewicz JJ. The effect of intravenous prostaglandin $F_{2} \alpha$ and $E_{2}$ on the motility of sigmoid colon. Gut 1975; 16: 47-9.

11 Misiewicz JJ, Waller SL, Kiley N, Horton EW. Effect of oral prostaglandin $\mathrm{E}_{1}$ on intestinal transit in man. Lancet 1969; i: 648-51.

12 Rush BD, Ruwart MJ. The role of accelerated colonic transit in prostaglandin-induced diarrhoea and its inhibition by prostacyclin. Br J Pharmacol 1984; 83: 157-9.

13 Duggan DE, Hooke KF, Noll RM, Chiu Kwan K. Enterohepatic circulation of indomethacin and its role in intestinal irritation. Biochem Pharmacol 1975; 25: 1749-54.

14 Piper PJ, Vane JR, Wyllie JH. Inactivation of prostaglandins by the lungs. Nature 1970; 225: 600-4.

15 Hostein J, Janssens J, Vantrappen G, Peeters TL, Vandeweerd M, Leman G. Somatostatin induces ectopic activity fronts of the migrating motor complex via a local intestinal mechanism. Gastroenterology 1984; 87: 1004-8.

16 Hachet T, Buéno L, Fioramonti J, Rode C. The use of a compact portable microcomputer system (Epson HX $20)$ to measure on-line the contractile activity of the digestive tract from 8 channels. Application to pharmacological tests. J Pharmacol Meth 1986; 16: 171-80.

17 Karaus M, Sarna SK. Giant migrating contractions during defecation in the dog colon. Gastroenterology 1987; 92: 925-33.

18 Karaus M, Sarna SK, Ammon HV, Wienbeck M. Effects of oral laxatives on colonic motor complexes in dogs. Gut 1987; 28: 1112-9.

19 Stewart JJ, Bass P. Effects of ricinoleic and oleic acids on the digestive contractile activity of the canine small and large bowel. Gastroenterology 1976; 70: 371-6. 
20 Binder HJ. Pharmacology of laxatives. Ann Rev Pharmacol Toxicol 1977; 17: 355-67.

21 Fioramonti J, Droy-Lefaix MT, Buéno L. Changes in gastrointestinal motility induced by cholera toxin and experimental osmotic diarrhoea in dogs: effects of treatment with an argillaceous compound. Digestion 1987; 36: 230-7.

22 Leng-Peschlow E. Dual effect of orally administered sennosides on large intestine transit and fluid absorption in the rat. $J$ Pharm Pharmacol 1986; 38: 606-10.

23 Burch RM, Wise WC, Halushka PV. Prostaglandinindependent inhibition of calcium transport by nonsteroidal anti-inflammatory drugs: differential effects of carboxylic acids and piroxicam. J Pharmacol Exp Ther
1983; 227: 84-91.

24 Leng-Peschlow E. Acceleration of large intestine transit time in rats by sennosides and related compounds. J Pharm Pharmacol 1986; 38: 369-73.

25 Thiery M, Decoster JM, Parewijck W, Noah MC, Derom R, Van Kets H. Endocervical $\mathrm{PGE}_{2}$ gel for preinduction cervical softening. Prostaglandins 1984; 27: 429-39.

26 Beubler E, Juan H. Effect of ricinoleic acid and other laxatives in net water flux and prostaglandin $E$ release by the rat colon. J Pharm Pharmacol 1979; 31: 681-5.

27 Capasso F, Mascolo N, Autore G, Romano V. Laxatives and the production of autacoids by rat colon. J Pharm Pharmacol 1986; 38: 627-9. 